\title{
Trends in Antifungal Susceptibility of Candida Species - one Year Observation
}

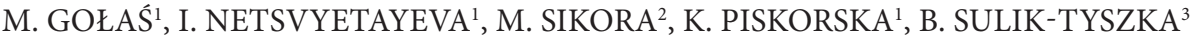 \\ and E. SWOBODA-KOPEĆ ${ }^{2,3}$

\begin{abstract}
${ }^{1}$ Department of Medical Microbiology, Warsaw Medical University, Warsaw, Poland ${ }^{2}$ Department of Dental Microbiology, Warsaw Medical University, Warsaw, Poland ${ }^{3}$ Department of Microbiology, Central Clinical Hospital, Warsaw, Poland
\end{abstract}

Submitted 20 August 2013, revised 13 January 2014, accepted 12 May 2014

\begin{abstract}
In the past years opportunistic fungal infections have seriously increased, mainly in immunocompromised patients. The aim of the study was to determine the prevalence of yeast-like fungi in invasive candidiasis and to estimate its susceptibility to chosen antifungal agents. One hundred and sixty strains of yeast-like fungi were cultured from various clinical material: samples from lower respiratory tract, blood, the peritoneal cavity and others. The susceptibility tests were established according to the quantitative E-test method. The Candida genus represented the main etiological factor of invasive candidiasis. The predominant species were: C. glabrata (71/160), C. albicans (34/160), C. krusei (17/160), C. tropicalis (14/160). All tested strains were the most resistant to itraconazole. Candida glabrata presented the $100 \%$ susceptibility to amphotericin B and caspofungin and was the least susceptible to itraconazole, posaconazole and voriconazole. Candida albicans was the most susceptible species to all antymicotics.
\end{abstract}

Ke y wo rds: Candida glabrata, antifungal susceptibility, Candidiasis, E-test

\section{Introduction}

In the past years, opportunistic fungal infections have seriously increased, mainly in immunocompromised patients. Systemic mycoses are most often caused by Candida genus yeasts and moulds, especially the Aspergillus genus. The increasing number of infections often results from advanced and more aggressive medical treatment, such as chemotherapy, abdominal or cardiothoracic surgery complications, organs and hematopoietic cells transplantation, prolonged broad spectrum antibiotic therapy, biopolymer devices such as indwelling catheters and prolonged hospitalization (Passos et al., 2007).

According to data published by many authors, C. albicans isolated from clinical materials remains to be the predominant pathogen. The percentage of infections caused by this microorganism varied from $48.5 \%$ (Passos et al., 2007) to 72.7\% (Kubisiak-Rzepczyk et al., 2008) depending on localisation of the infection and sample origin. In spite of a broad antifungal prophylaxis, these infections still represented a severe therapeutic problem (Cuenca-Estrella et al., 2002; Nucci et al., 2005; Laupland et al., 2005; Passos et al., 2007; Batura-Gabryel 2007; Kubisiak-Rzepczyk et al., 2008).
Candida glabrata is one of the most frequently isolated non-albicans Candida species (Lockhart et al., 1999; Fadda et al., 2008; Costa de Oliveira et al., 2011). Especially it was a frequent cause of candidaemia in patients from high risk group (Lockhart et al., 1999). In the p ast years, C. glabrata infections have increased possibly as a result of wide use of azoles that promote rapid selection of resistance (Fadda et al., 2008; Costa de Oliveira et al., 2011). Lockhart et al. showed that C. glabrata was a second most common pathogen of candidaemia and its prevalence was increasing (Lockhart et al., 1999).

The percentage of infections caused by non-albicans Candida species (NAC spp.) constantly increase, but their number does not exceed the number of infections caused by C. albicans. Different species of non-albicans Candida spp. predominated in infections depending on the study and geographical location. C. parapsilosis caused $36.4 \%$ of infections in Latin America, and the percentage of infections other than C.albicans represented approx. 65\% (Cuenca-Estrella et al., 2002; Berg von Zepelin etal., 2007; Saracli etal., 2009). C.glabrata and C.parapsilosis are indicated as the second etiological factor in yeast infections. A higher number of C. glabrata infections could result from

\footnotetext{
* Corresponding author: M. Gołaś, Department of Medical Microbiology, Warsaw Medical University, Chałubinskiego Str 5, 02-004 Warsaw, Poland; phone/fax: +48 226282739; e-mail: marlena.gol@gmail.com
} 
the widespread use of fluconazole (Nucci et al., 2005; Laupland et al., 2005).

Among non-albicans Candida species causing infections, C. parapsilosis, C. tropicalis and C. glabrata were most often isolated, and less often were isolated: C. $\mathrm{kru}$ sei, C. guilliermondii, C. kefyr, C. lusitaniae and C. inconspicua (Cuenca-Estrella et al., 2002; Laupland et al., 2005; Nucci et al., 2005; Passos et al., 2007; KubisiakRzepczyk et al., 2008; Pfaller et al., 2008).

This study was performed to evaluate species distribution, antifungal susceptibility and also contemporary epidemiology in Polish hospital.

\section{Experimental}

\section{Materials and Methods}

The study was conducted from September 1, 2009 to August 31, 2010 at the Central Clinical Hospital in Warsaw. Strains were collected from hospitalized patients with diagnosed fungal infections (fungal infection was identified when strain was isolated from sterile body sites, or when the same species was isolated at least from 3 different body sites) on 15 wards.

Clinical samples originated from: lower respiratory tracts: tracheal aspirates (56), bronchovesicular lavage (BAL) (15) and sputum (11), blood (25), peritoneal cavity samples (16), bile tracts samples (9) and other different clinical materials (28).

The samples were cultured on standard Sabouraud Dextrose Agar with gentamicin and chloramphenicol (bioMeriéux, Marcy l'Etoile, France). Blood was cultured on enriched fluid medium within the Bact/ Alert automatic system (bioMeriéux, Marcy l'Etoile, France). Species identification was carried out using commercial biochemical tests ID32C (bioMeriéux, Marcy l'Etoile, France).

The quality control strains used in every batch of susceptibility test were Candida parapsilosis ATCC 22019 and Candida albicans ATCC 90028 (CLSI, 2000).

Inoculum preparation for susceptibility test: The inocula were prepared following the guidelines of Clinical Laboratory Standards Institute (CLSI, 2000) Document M27-A2. After preparing 24h cultures of the isolates at $37^{\circ} \mathrm{C}, 5$ colonies were suspended in a sterile test tube containing $1 \mathrm{~mL}$ of $0.85 \% \mathrm{NaCl}$ for each isolate. The mixture was vortexed at low speed to obtain homogeneity. The cell density was equivalent to $0.5 \mathrm{McFarland}$ standards. Antifungal agents used in this test: amphotericin B, fluconazole, posaconazole, voriconazole, itraconazole, caspofungin (bioMeriéux, Marcy l'Etoile, France). All strips were stored at $-20^{\circ} \mathrm{C}$ and thawed at room temperature before use.

All isolates were tested in vitro against 6 antifungal agents standard used in mycological diagnostic and recommended for treatment invasive candidiasis: amphotericin B, fluconazole, posaconazole, voriconazole, itraconazole and caspofungin. Lawn cultures of the Candida isolates were prepared on RPMI-1640 agar medium (Biomed, Warsaw, Poland) supplemented with $2 \%$ glucose ( $\mathrm{pH}$ 7.0) in Petri dishes. E-test (bioMeriéux, Marcy l'Etoile, France) strips were gently placed on the lawn cultures with the MIC scale facing upwards using a sterile forcep. The Petri dishes were incubated at $37^{\circ} \mathrm{C}$ for $24 \mathrm{~h}$. The MIC's value were read where the inhibition ellipse intersected the strip which was interpreted at the lowest concentration at which $80 \%$ of the growth was inhibited for the azoles group and $100 \%$ of the growth was inhibited for the amphotericin B and echinocandins. The result interpretation was performed by MIC determination within clinical categories (S, I or $\mathrm{R})$ according to CLSI recommendations.

\section{Results}

From September 1, 2009 to August 31, 2010, a total of 17387 clinical materials were tested for yeast presence. One thousand six hundred ninety one positive culture samples were analyzed, among them 160 isolates were cultured from patients with invasive candidiasis. Ninety six percent of this infection were caused by Candida spp.

There were 71 isolates $(71 / 160,44.4 \%)$ of C. glabrata, 34 of C.albicans, 17 of C. krusei, 14 of C. tropicalis and seven of both C.inconspicua and C.parapsilosis. Figure 1 presents the distribution of the eight most common species.

Other than Candida spp. isolates cultured during the study period were: Saccharomyces cerevisiae (5/160, $3 \%)$, Trichosporon asahii (1/160, 0.6\%), and Geotrichum capitatum $(1 / 160,0.6 \%)$.

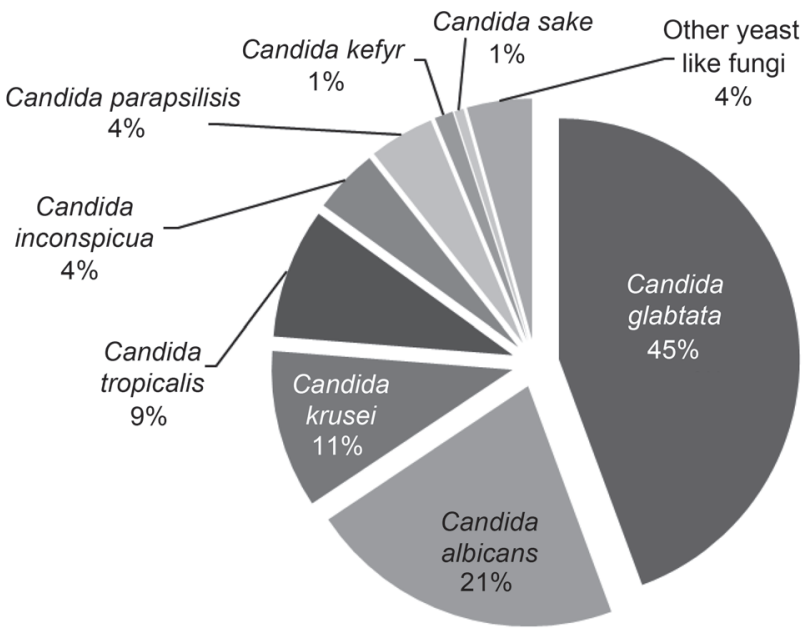

Fig. 1. Distribution of Candida species causing invasive fungal infection during the study period. 


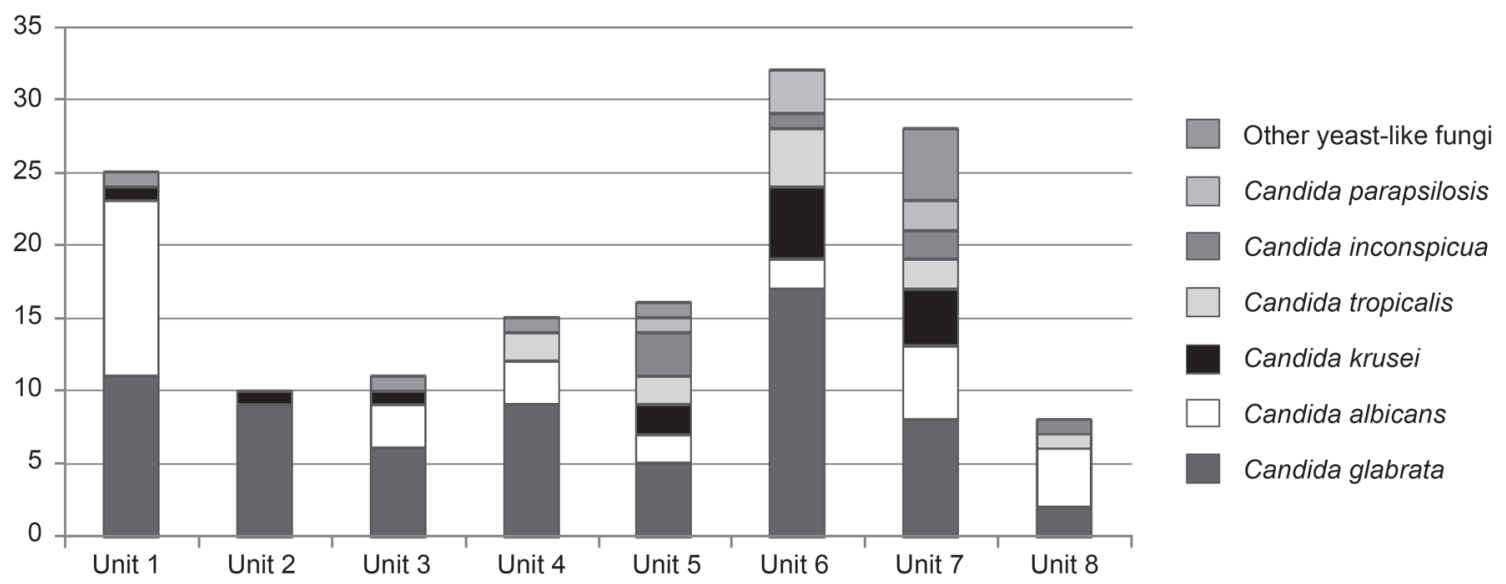

Unit 1. Department of General, Gastroenterological and Oncological Surgery

Unit 2. Department of General, Vascular and Transplant Surgery

Unit 3. Department of Hematology

Unit 4. Department of Internal Medicine, Pneumonology, and Allergology

Unit 5. Department of Immunology, Transplantology and Internal Medicine, Transplantation Institute

Unit 6. Department of Cardiac Surgery

Unit 7. Intensive Care Unit

Unit 8. Intensive Care Unit A

Fig. 2. Distribution of the yeast like fungi according to medical unit

The distribution of isolated Candida species in predominated wards is presented in Figure 2. C. glabrata dominated in almost all Surgery Units with range, $31.25-81.8 \%$ and $60 \%$ in Department of Internal Medicine, Pneumonology, and Allergology. Regarding C. albicans with $48 \%$ of the species isolated from Department of General, Gastroenterological and Oncological Surgery. Also frequently cultured in ICUs with range, $17.8-50 \%$.

C. glabrata strains were mainly isolated from tracheal aspirates (26/71), material from peritoneal cavity (9/71) and - bronchovesicular washing samples (8). C. albicans was mostly isolated from blood - 18 strains. Also from tracheal aspirate 8 strains of C. krusei were isolated.

The susceptibility to antifungal agents of the isolated Candida species are presented in Table I. Data are reported as MIC ranges, $\mathrm{MIC}_{90}$, number of susceptible isolates and number of resistant isolates. Best activity against all species tested exhibited amphotericin B (100\% susceptible strains) and caspofungin (100\% susceptible strains). Caspofungin were potent against all species with the $\mathrm{MIC}_{90}$ range: $0.016 \mathrm{mg} / \mathrm{l}$ for C. kefyr to $0.5 \mathrm{mg} / \mathrm{l}$ for C.parapsilosis. Sixty six (93\%) of the 71 C. glabrata showed resistance to itraconazole. Nineteen (12\%) of the 160 isolates were intermediate resistant to itraconazole, including six C. inconspicua, three C. krusei, three C. tropicalis and one of each species: C.glabrata, C.albicans, C. parapsilosis, C. kefyr and C. sake. All isolates were susceptible to voriconazole except for three resistant and four intermediate resistant isolates of C.glabrata. Overall, fluconazole exhibited good activity against most species (98\%), with $\mathrm{MIC}_{90}$ range, $1 \mathrm{mg} / \mathrm{l}-16 \mathrm{mg} / \mathrm{l}$. In particular, C. albicans, C. tropicalis, C. parapsilosis, C. kefyr and C. sake. In contrast, C. inconspicua was less susceptible to fluconazole $\left(\mathrm{MIC}_{90}, 16 \mathrm{mg} / \mathrm{l}\right)$. All isolates were susceptible to posaconazole except for 15 resistant strains of C. glabrata.

All triazoles demonstrated potent activity against C. albicans (susceptible 99.25\%), C. parapsilosis (susceptible $96.43 \%$ ) and C. sake (susceptible 100\%). Regarding C.glabrata, 4/71 isolates resulted susceptible to itraconazole, and 56/71 isolates resulted susceptible to voriconazole. C. glabrata was the least susceptible species to itraconazole $\left(\mathrm{MIC}_{90^{\circ}}>32 \mathrm{mg} / \mathrm{l}\right)$, posaconazole $\left(\mathrm{MIC}_{90}, 1.5 \mathrm{mg} / \mathrm{l}\right)$ and voriconazole $\left(\mathrm{MIC}_{90}, 1.5 \mathrm{mg} / \mathrm{l}\right)$.

\section{Discussion}

Resistance to microbial agents emerges and spreads as a consequence of the use antimicrobial drugs. Similarly to other candidaemia studies, (Martin etal., 2005; Tortorano etal., 2006; Borg von Zepelin etal., 2007; Chen et al., 2009; Swinne et al., 2009; Tortorano et al., 2009; Falagas et al., 2010; Nishikaku et al., 2010; Arendrup et al., 2011; Arendrup et al., 2011) the highest number of infections was reported from Surgery, ICU and Hematology units. Yeast like fungi appeared as the predominant factor in invasive fungal infection at the Central Clinical Hospital. Over the past ten years, studies reported a shift in the etiology of candidaemia. While Candida albicans is still considered 
Table I

MICs and antifungal susceptibility of Candida species

\begin{tabular}{|c|c|c|c|c|c|c|c|c|c|}
\hline \multirow{2}{*}{$\begin{array}{l}\text { Species } \\
\text { (isolates) }\end{array}$} & \multicolumn{3}{|c|}{ Amphotericin B } & \multicolumn{3}{|c|}{ Fluconazole } & \multicolumn{3}{|c|}{ Itraconazole } \\
\hline & $\begin{array}{l}\text { Range } \\
{[\mathrm{mg} / \mathrm{l}]}\end{array}$ & $\begin{array}{l}\mathrm{MIC}_{90} \\
{[\mathrm{mg} / \mathrm{l}]}\end{array}$ & S/R S\% & $\begin{array}{l}\text { Range } \\
{[\mathrm{mg} / \mathrm{l}]}\end{array}$ & $\begin{array}{l}\mathrm{MIC}_{90} \\
{[\mathrm{mg} / \mathrm{l}]}\end{array}$ & S/R S\% & $\begin{array}{l}\text { Range } \\
{[\mathrm{mg} / \mathrm{l}]}\end{array}$ & $\begin{array}{l}\mathrm{MIC}_{90} \\
{[\mathrm{mg} / \mathrm{l}]}\end{array}$ & S/R S\% \\
\hline C. glabrata (71) & $0.032-0,38$ & 0.25 & $71 / 0100$ & not tested & - & not tested & $0.023-32$ & $>32$ & $4 / 1 / 665.6$ \\
\hline C. albicans (34) & $0.004-0,19$ & 0.094 & $34 / 0100$ & $0,016-2$ & 1 & $26 / 0100$ & $0.012-0.25$ & 0.125 & $33 / 1 / 097$ \\
\hline C. krusei (17) & $0.047-0,5$ & 0.38 & $17 / 0100$ & not tested & - & not tested & $0, .16-32$ & 0.5 & $12 / 3 / 270.6$ \\
\hline C. tropicalis (14) & $0.047-0,5$ & 0.38 & $14 / 0100$ & $0.25-3.0$ & 3 & $3 / 0100$ & $0.064-1.5$ & 1 & $9 / 3 / 264.3$ \\
\hline C. parapsilosis (7) & $0.016-0.25$ & 0.125 & $7 / 0100$ & $1.5-6.0$ & 6 & $2 / 1100$ & $0.023-0.25$ & 0.125 & $6 / 1 / 0857$ \\
\hline C. inconspicua (7) & $0.006-0.094$ & 0.094 & $7 / 0100$ & $6.0-16.0$ & 16 & $5 / 183$ & $0.125-0.5$ & 0.38 & $1 / 6 / 014.3$ \\
\hline C. kefyr (2) & $0.125-0.19$ & 0.125 & $2 / 0100$ & 1 & 1 & $2 / 0100$ & $0.5-1.0$ & 1 & $0 / 1 / 10$ \\
\hline C. sake (1) & 0094 & - & $1 / 0100$ & 8 & - & $1 / 0100$ & 0.38 & - & $0 / 1 / 00$ \\
\hline
\end{tabular}

\begin{tabular}{|c|c|c|c|c|c|c|c|c|c|}
\hline \multirow{2}{*}{$\begin{array}{c}\text { Species } \\
\text { (isolates) }\end{array}$} & \multicolumn{3}{|c|}{ Voriconazole } & \multicolumn{3}{|c|}{ Posaconazole } & \multicolumn{3}{|c|}{ Caspofungin } \\
\hline & $\begin{array}{l}\text { Range } \\
{[\mathrm{mg} / \mathrm{l}]}\end{array}$ & $\begin{array}{l}\mathrm{MIC}_{90} \\
{[\mathrm{mg} / \mathrm{ll}]}\end{array}$ & S/R S\% & $\begin{array}{l}\text { Range } \\
{[\mathrm{mg} / \mathrm{l}]}\end{array}$ & $\begin{array}{l}\mathrm{MIC}_{90} \\
{[\mathrm{mg} / \mathrm{l}]}\end{array}$ & S/R S\% & $\begin{array}{l}\text { Range } \\
{[\mathrm{mg} / \mathrm{l}]}\end{array}$ & $\begin{array}{l}\mathrm{MIC}_{90} \\
{[\mathrm{mg} / \mathrm{l}]}\end{array}$ & S/R S\% \\
\hline C. glabrata (71) & $0.012-32$ & 1.5 & $64 / 4 / 390,2$ & $0.008-32$ & 1.5 & $56 / 1578.9$ & $0,032-0,19$ & 0,125 & $71 / 0100$ \\
\hline C. albicans (34) & $0.008-0.064$ & 0.032 & $34 / 0 / 0100$ & $0.016-0.19$ & 0.19 & $34 / 0100$ & $0,006-0,125$ & 0,125 & $33 / 0100$ \\
\hline C. krusei (17) & $0.016-0.38$ & 0.25 & $17 / 0 / 0100$ & $0.006-1.5$ & 0.19 & $17 / 0100$ & $0,094-0,5$ & 0,38 & $17 / 0100$ \\
\hline C. tropicalis (14) & $0.002-0.19$ & 0.125 & $14 / 0 / 0100$ & $0.032-0.19$ & 0.19 & $13 / 0100$ & $0,023-0,25$ & 0,125 & $14 / 0100$ \\
\hline C. parapsilosis (7) & $0.023-0.25$ & 0.125 & $7 / 0 / 0100$ & $0.023-0.125$ & 0.125 & $7 / 0100$ & $0,064-0,5$ & 0,5 & $7 / 0100$ \\
\hline C. inconspicua (7) & $0.064-0.19$ & 0.19 & $7 / 0 / 0100$ & $0.064-0.19$ & 0.125 & $6 / 0100$ & $0,047-0,125$ & 0,125 & $7 / 0100$ \\
\hline C. kefyr (2) & $0.032-0.047$ & 0.047 & $2 / 0 / 0100$ & $0.25-0.38$ & 0.38 & $2 / 0100$ & $0,012-0,016$ & 0,016 & $2 / 0100$ \\
\hline C. sake (1) & not tested & - & not tested & 0.064 & - & $1 / 0100$ & 0,064 & - & $1 / 0100$ \\
\hline
\end{tabular}

the most common etiological factor of candidaemia (Laupland etal., 2005; Passos et al., 2007; KubisiakRzepczyk et al., 2008; Macura et al., 2009; Saracli et al., 2009; Swinne et al., 2009), recent epidemiologic studies have demonstrated an increasing incidence of non albicans species candidaemia, with C. glabarata, C. krusei, C. tropicalis, C. parapsilosis (Nguyen et al., 1996; Rocco etal., 2000; Richet etal., 2002; Wisplinghoff et al., 2004; Basetti et al., 2006). The reason for change in the pattern of Candida spp distribution has not been understood yet, but there are some predisposing factors identified, such as indwelling catheters and parenteral nutrition for C. parapsilosis (Horasan et al., 2010), cancer and neutropenia for C. tropicalis (Negri et al., 2012) and previous exposure to azoles for C. krusei and C. glabrata (Bassetti et al., 2009) The results presented here demonstrate that non-C. albicans species caused the majority of cases of ICU. In our study C. glabrata was found to cause $44,4 \%$ of the cases of IFI. This is similar to the proportion of cases of infections caused by C. glabrata that the Ruan et al. found in its latest study (Ruan et al., 2009). C. albicans was ranked as second etiological factor of candidaemia, causing $21,25 \%$ of invasive infections. Third and fourth came C. krusei and C. tropicalis causing respectively $10,6 \%$ and $8,75 \%$ of infections. These study results are similar to those in
North America (Trick et al., 2002) and Ireland (McMullan et al., 2002) in which the prevalence of non-albicans Candida is higher than that of C. albicans.

The emergence of C. glabrata as the major non-albicans Candida species was not suprising given its ability to develop resistance to azole drugs and expand under the selection pressure provided by the common use of fluconazole and itraconazole for prophylaxis, preemptive therapy and empirical therapy, discriminately or indiscriminately in high risk settings (Hitchcock et al., 1993; Rex et al., 1995; Gumbo et al., 1999; Sobel 2000; Safdar etal., 2001; Uzun etal., 2001; Vazques etal., 2001; Cuenca-Estrella et al., 2002; Passos et al., 2007; Kubisiak-Rzepczyk et al., 2008; Saracli etal., 2009). Antifungal resistance in our study was a rare finding and was restricted to azoles. As with a Spanish study (Cisterna et al., 2010), none of our Candida bloodstream isolates and other isolates from invasive fungal infections had MICs of $>2 \mathrm{mg} / \mathrm{l}$ for amphotericin B. According to E-test interpretative criteria, all of the C.albicans, C.tropicalis, C.parapsilosis, C. kefyr and C. sake isolates included here were susceptible to fluconazole (MIC $\leq 8 \mathrm{mg} / \mathrm{l})$, voriconazole (MIC $\leq 1 \mathrm{mg} / \mathrm{l}$ ) and posaconazole $(\mathrm{MIC} \leq 0.5 \mathrm{mg} / \mathrm{l})$. Voriconazole was fully-active against all C. krusei isolates but only in $90.2 \%$ of isolates of C. glabrata, while only $4 / 71$ 
C. glabrata isolates were susceptible to itraconazole, and 66/71 and 2/17 C. krusei isolates were resistant to this drug. Our proportion of fluconazole-resistant isolates $(2.2 \%)$ was lower than the rates observed with European (6.3\%) and North America (6.6\%) isolates (Messer et al. 2009; Cisterna et al., 2010). Caspofungin demonstrated excellent activity as reported by others (Pffaler et al., 2011). The azole which exhibited the best in vitro activity was voriconazole. Also other authors shows similar results (Berg von Zepelin et al., 2007; Fleck et al., 2007; González et al., 2008; Swinne et al., 2009).

Macura et al. observed C. albicans high susceptibility to amphotericin B and fluconazole, strains tested in our study were also highly susceptible to this agents. (Macura et al., 2009). The data presented in our paper demonstrated a high biological activity of posaconazole (89.7\% of the strains).

In conclusion yeast like fungal strains belonging to non-albicans Candida species represented the main cause of invasive fungal infections with predominant azole resistant species such as: Candida glabrata (71/160) and C. krusei (17/160). We reported that all isolated Candida species strains were susceptible to amphotericin B and caspofungin. Analysed strains were most resistant to itraconazole. A similar observation was described by Swinne et al. (Swinne et al., 2009) and other authors (Berg von Zepelin et al., 2007; Szymankiewicz et al., 2007; González et al., 2008; Saracli et al., 2009; Sipsas et al., 2009). Due to increasing MICs (intermediate-resistant and resistant strains), itraconazole must be used with caution for the treatment of invasive candidiasis due to C. glabrata and C. krusei. Periodic analysis is critical in determining the rapidly evolving susceptibility trends among Candida species, especially at centers caring for patients at risk.

\section{Acknowledgements}

This paper was supported by the Polish State Committee for Scientific Research (grant No. N N401 042738).

\section{Conflict of interest}

No conflict of interest.

\section{Literature}

Arendrup M.C., B. Bruun, J.J. Christensen, K. Fuursted, H.K. Johansen, P. Kjaeldgaard, J.D. Knudsen, L. Kristensen, J. Møller, L. Nielsen and others. 2011. National surveillance of fungemia in Denmark 2004 to 2009. J. Clin. Microbiol. 49: 325-334.

Arendrup M.C., S. Sulim, A. Holm, L. Nielsen, S.D. Nielsen, J.D. Knudsen, N.E. Drenck, J.J. Christensen and H.K. Johansen. 2011. Diagnostic issues, clinical characteristics, and outcomes for patients with fungemia. J. Clin. Microbiol. 49: 3300-3308.
Bassetti M., F. Ansaldi, L. Nicolini, E. Malfatto, M.P. Molinari, M. Mussap, B. Rebesco, F. Bobbio Pallavicini, G. Icardi and C. Viscoli. 2009. Incidence of candidaemia and relationship with fluconazole use in an intensive care unit. J. Antimicrob. Chemother. 64: 625-629.

Batura-Gabryel H. Deep mycoses in Poland - candidosis [in:] Medical Mycology Medical Doctor and Students. (in Polish) Editor: Adamski Z., Batura-Gabryel H., Wydawnictwo Naukowe Uniwersytetu Medycznego im. Karola Marcinkowskiego w Poznaniu. Poznan, Poland, 2007: 90-96.

Borg von Zepelin M., L. Kunz, R. Rüchel, U. Reichard, M. Weig and U. Gross. 2007. Epidemiology and antifungal susceptibilities of Candida spp. to six antifungal agents: results from a surveillance study on fungemia in Germany from July 2004 to August 2005, J. Antimicrob. Chemother. 60: 424-428.

Chen S.C., D. Marriott, E.G. Playford, Q. Nguyen, D. Ellis, W. Meyer, T.C. Sorrell, M. Slavin, Australian Candidaemia Study. 2009. Candidaemia with uncommon Candida species: predisposing factors, outcome, antifungal susceptibility, and implications for management. Clin. Microbiol. Infect. 15: 662-669.

Cisterna R., G. Ezpeleta, O. Telleria, Spanish Candidemia Surveillance Group. 2010. Nationwide sentinel surveillance of bloodstream Candida infections in 40 tertiary care hospitals in Spain. J. Clin. Microbiol. 48: 4200-4206.

Costa de Oliveira S., I. Marcos Miranda, R.M. Silva, E. Pinto, A. Silva, R. Rocha, A. Amorim, A. Gonçalves Rodrigues and C. Pina-Vaz. 2011. FKS2 Mutations Associated with Decreased Echinocandin Susceptibility of Candida glabrata following Anidulafungin Therapy, Antimicrob. Agents. Chemother. 55(3): 1312-1314. Cuenca-Estrella M., L. Rodero, G. García-Effrón and J.L. Rodriguez-Tudela. 2002. Antifungal susceptibilities of Candida spp. isolated from blood in Spain and Argentina, 1996-1999, J. Antimicrob. Chemother. 49: 981-987.

Fadda M.E., G.S. Podda, M.B. Pisano, M. Deplano and S. Cosentino. 2008. Prevalence of Candida species in different hospital wards and their susceptibility to antifungal agents: results of a three year survey, J. Prev. Med. Hyg. 49(2): 69-74.

Falagas M.E., N. Roussos and K.Z. Vardakas. 2010. Relative frequency of albicans and the various non-albicans Candida spp. among candidemia isolates from inpatients in various parts of the world: a systematic review. Int. J. Infect. Dis. 14: e954-e966.

Fleck R., A. Dietz and H. Hof. 2007. In vitro susceptibility of Candida species to five antifungal agent in a German university hospital assessed by the reference broth microdilution method and Etest, J. Antimicrob. Chemother. 59: 767-771.

González M.G., M. Elizondo and J. Atala. 2008. Trends in Species Distribution and Susceptibility of Bloodstream Isolates of Candida Collected in Monterrey, Mexico, to Seven Antifungal Agents: Results of a 3-Year (2004 to 2007) Surveillance Study, J. Clin. Microbiol. 46: 2902-2905.

Gumbo T., C.M. Isada, G. Hall, M.T. Karafa and S.M. Gordon. 1999. Candida glabrata fungemia. Clinical features of 139 patients. Medicine 78: 220-227.

Hitchcock C.A., G.W. Pye, P.F. Troke, E.M. Johnson and D.W Warnock. 1993. Fluconazole resistance in Candida glabrata. Antimicrob. Agents Chemother. 37: 1962-1965.

Horasan E.S., G. Ersöz, M. Göksu, F. Otag, A.O. Kurt, S. Karaçorlu and A. Kaya. 2010. Increase in Candida parapsilosis fungemia in critical care units: a 6-years study. Mycopathologia 170: 263-268. Kalkanci A., E. Berk, B. Aykan, K. Caglar, K. Hizel, D. Arman and S. Kustimur. 2007. Epidemiology and antifungal susceptibility of Candida species isolated from hospitalized patients. J. Mycol. Méd. 17: 16-20.

Kubisiak-Rzepczyk H., E. Szponar and Z. Adamski. 2008. The evaluation of the qualitative and susceptibility testing of Candida 
species isolated from the oral cavity plate denture users (in Polish). Dental Forum 1: XXXVI.

Kucharíková S., P. Van Dijc, M. Lisalová and H. Bujdáková. 2010. Effect of antifungals on itraconazole resistant C.glabrata. Cent Europ. J. Biology 5: 318-323.

Laupland K.B., B.D. Gregson, D.L. Church, T. Ross and S. Elsayed. 2005. Invasive Candida species infections: a 5 year population-based assessment, J. Antimicrob. Chemother. 56: 532-537.

Lockhart S.R., S. Joly, K. Vargas, J. Swails-Wenger, L. Enger and D.R. Soll. 1999. Natural defenses against Candida colonization breakdown in the oral cavities of the elderly. J. Dent. Res. 78: 857-868.

Macura A.B. and M. Skóra. 2009. Antifungal susceptibility testing of fungi isolated from vagina. (in Polish). Mikol. Lek. 16: 206-209. Martin D., F. Persat, M.A. Piens and S. Picot. 2005. Candida species distribution in bloodstream cultures in Lyon, France, 19982001. Eur. J. Clin. Microbiol. Infect. Dis. 24: 329-333.

McMullan R., R. McClurg, J. Xu, J.E. Moore, B.C. Millar, M. Crowe and S. Hedderwick. 2002. Trends in the epidemiology of Candida bloodstream infections in Northern Ireland between January 1984 and December 2000. J. Infect. 45: 25-28.

Messer S.A., G.J. Moet, J.T. Kirvy and R.N. Jones. 2009. Activity of contemporary antifungal agents, including the novel echinocandin anidulafungin, tested against Candida spp., Cryptococcus spp., and Aspergillus spp.: report from the SENTRY antimicrobial surveillance program (2006 to 2007). J. Clin. Microbiol. 47: 1942-1946.

Negri M., S. Silva, M. Henriques and R. Oliveira. 2012. Insights into Candida tropicalis nosocomial infections and virulence factors. Eur. J. Clin. Microbiol. Infect. Dis. 31: 1399-412.

Nguyen M.H., J.E. Peacock, A.J. Morns, D.C. Tanner, M.L. Nguyen, D.R. Snydman, M.M. Wagener, M.G. Rinaldi and V.L. Yu. 1996. The changing face of Candidemia: emergence of non-Candida albicans species and antifungal resistance. Am. J. Med. 100: 617-623. Nishikaku A.S., Melo A.S.A. and Colombo A.L. 2010. Geographic trends in invasive Candidiasis. Curr Fungal Infect Rep. 4: 210-8. Nucci M., Marr A.K. 2005. Emerging fungal diseases. Clin. Infect. Dis. 41: 521-526.

Passos X.S., Costa C.R., Araújo C.R., Nascimento E.S., Souza L.K., Fernandes Ode F., Sales W.S. and Silva Mdo. R. 2007. Species distribution and antifungal susceptibility patterns of Candida spp. bloodstream isolates from a Brazilian tertiary care hospital, Mycopathologia 163: 145-151.

Pfaller M.A., L. Boyken, R. Hollis, J. Kroeger, S.A. Messer, S. Tendolkar and D.J. Diekema. 2008. In vitro Susceptibility of Invasive Isolates of Candida spp. To Anidulafungin, Caspofungin, and Micafungin: Six Years of Global Surveillance. J. Clin. Microbiol. 46: 150-156.

Pfaller M.A., M. Castanheira, S.A. Messer, G.J. Moet and R.N. Jones. 2011. Echinocandin and triazole antifungal susceptibility profiles for Candida spp., Cryptococcus neoformans, and Aspergillus fumigatus: application of new CLSI clinical breakpoints and epidemiologic cutoff values to characterize resistance in the SENTRY Antimicrobial Surveillance Program (2009). Diagn. Microbiol. Infect. Dis. 69: 45-50.

Pfaller M.A., D.J. Diekema, M. Rinaldi, R. Barnes, B. Hu, A.V. Veselov, N. Tiraboschi, E. Nagy and D.L. Gibbs. 2005. Results from the ARTEMIS DISK Global Antifungal Surveillance Study: a 6.5-Year Analysis of Susceptibilities of Candida and Other Yeast Species to Fluconazole and Voriconazole by Standardized Disk Diffusion Testing: J. Clin. Microbiol. 43: 5848-5859.
Rex J.H., M.G. Rinaldi and M.A. Pfaller. 1995. Resistance of Candida species to fluconazole. Antimicrob. Agents Chemother. 39:1-8. Ruan S.Y., Y.T. Huang, C.C. Chu, C.J. Yu and P.R. Hsueh. 2009. Candida glabrata fungaemia in a tertiary centre in Taiwan: antifungal susceptibility and outcomes. Int. J. Antimicrob. Agents. 34(3): 236-239.

Safdar A., F. van Rhee, J.P. Henslee-Downey, S. Singal and J. Mehta. 2001. Candida glabrata and Candida krusei fungemia after high-risk allogeneic marrow transplantation: no adverse effect of low-dose fluconazole prophylaxis on incidence and outcome. Bone Marrow Transplant. 28: 873-878.

Saracli M.A., R. Gumral, H.C. Gul, A. Gonlum and S.T. Yildiran. 2009. Species distribution and in vitro susceptibility of Candida bloodstream isolates to six new and current antifungal agents in a Turkish Tertiary Care Military Hospital, recovered through 2001 and 2006, Milit. Med. 174: 860-865.

Sipsas N.V., R.E. Lewis, I.I. Raad and D.P Kontoyiannis. 2009. Monotherapy with caspofungin for candidaemia in adult patients with cancer: a retrospective, single institution study. Internat. J. Antimicrob. Agents. 34: 95-98.

Sobel J.D. 2000. Management of infections caused by Candida glabrata. Curr. Infect. Dis. Rep. 2: 424-428.

Swinne D., N. Nolard, P. Van Rooij and M. Detandt. 2009. Short report Bloodstream yeast infections: a 15 - month survey. Epidemiol Infect Cambridge University Press. 137: 1037-1040.

Szymankiewicz M. 2007. In vitro susceptibility of C. parapsilosis strains isolated from diffrent clinical materials to fluconazole (in Polish). Mikol. Lek. 14: 37-40.

Szymankiewicz M. and M. Dancewicz. 2008. Evaluation of voriconazole and caspofungin in vitro activity against Candida spp. strains using E-test method. (in Polish) Mikol. Lek. 15: 13-15.

Tortorano A.M., C. Kibbler, J. Peman, H. Bernhardt, L. Klingspor and R. Grillot. 2006. Candidaemia in Europe: epidemiology and resistance. Int. J. Antimicrob. Agents. 27: 359-66.

Tortorano A.M., J. Peman, H. Bernhardt, L. Klingspor, C.C. Kibbler, O. Faure, E. Biraghi, E. Canton, K. Zimmermann, S. Seaton and others. 2004. Epidemiology of candidaemia in Europe: results of 28-month European Confederation of Medical Mycology (ECMM) hospital-based surveillance study. Eur. J. Clin. Microbiol. Infect. Dis. 23: $317-22$.

Trick W.E., S.K. Fridkin, J.R. Edwards, R.A. Hajjeh and R.P. Gaynes. 2002. National Nosocomial Infections Surveillance System Hospitals. Secular trend of hospital-acquired candidemia among intensive care unit patients in the United States during 1989-1999. Clin. Infect. Dis. 35: 627-630.

Uzun O., S. Ascioglu, E.J. Anaissie and J.H. Rex. 2001. Risk factors and predictors of outcome in patients with cancer and breakthrough candidemia. Antimicrob. Agents Chemother. 32: 1713-1717.

Vazquez J.A., G. Peng, J.D. Sobel, L. Steele-Moore, P. Schuman, W. Holloway and J.D. Neaton. 2001. Evolution of antifungal susceptibility among Candida species isolates recovered from human immunodeficiency virus-infected women receiving fluconazole prophylaxis. Clin. Infect. Dis. 33: 1069-1075.

Wieczorek P., P. Sacha, M. Żórawski, P. Jakoniuk and E. Tryniszewska. 2008. In vitro activity of caspofungin against strains of Candida (in Polish). Mikol. Lek. 15: 135-139.

Wisplinghoff H., T. Bischoff, S.M. Tallent, H. Seifert, R.P. Wenzel, M.B. Edmond. 2004. Nosocomial bloodstream infections in US hospitals: analysis of 24,179 cases from a prospective nationwide surveillance study. Clin. Infect. Dis. 1; 39(3): 309-17. 